\title{
Letter identification in relation to linguistic context and masking conditions*
}

\author{
ELIZABETH L. BJORK \\ University of Michigan, Ann Arbor, Michigan 48104 \\ and \\ WILLIAM K. ESTES \\ The Rockefeller University, New York, New York 10021
}

\begin{abstract}
With a two-choice detection procedure, identifiability of signal letters was determined in backgrounds of words, nonword letter strings, or homogeneous noise characters. Under high performance conditions of exposure duration and pre- and postmasks, there was a substantial advantage in identifiability of letters presented alone over letters embedded in words; under low performance conditions there were generally no differences between the two types of context, but some interactive effects appeared involving particular letters with serial position and type of background. No differences were obtained between word and nonword contexts. The disparities between these findings and those reported by Reicher (1969) and Wheeler (1970) may be related to the more complete elimination under the present procedures of effects of redundancy on response selection.
\end{abstract}

Two current lines of research on visual processing of character displays have yielded results which, on the surface at least, appear almost contradictory. Studies using the detection technique, and also those using simple report procedures in which the Ss know in advance the characters (usually a small set) to be reported, uniformly show that identifiability of a target letter declines as the number of other letters concurrently displayed increases (see, for example, Eriksen \& Rohrbaugh, 1970; Eriksen \& Spencer, 1969; Estes \& Wolford, 1971; Estes, 1972). The systematic character of the inhibitory effects of confusable noise letters upon recognizability of a target letter have been expressed in the interactive channels model of Estes (1972) and the computer simulation model of Shiffrin and Geisler (1972). On the other hand, studies of a type initiated by Reicher (1969) and Wheeler (1970), utilizing a modified detection procedure in which the Ss are informed of the alternative target letters between which they must choose on each trial by a postexposure cue, have reported that target letters embedded in words are more accurately identified than are the same letters presented alone for the same exposure duration.

If the apparently facilitative effect of embedding a letter in a word results from a perceptual process, then this phenomenon raises serious problems for the interactive channels model, which allows only for varying degrees of inhibitory interactions among inputs from the characters of a display. However, it is not entirely clear that factors having to do with short-term

*This research was supported in part by USPHS Grant GM16735 from the National Institute of General Medical Sciences. The authors are indebted to Edith Skaar for assistance with the conduct and analysis of the experiments. memory and response selection have been fully controlled in the experiments of Reicher and Wheeler.

First, it seems possible that the short-term memory load on the $\mathrm{S}$ is different when the relevant response alternatives of the trial are not made known to him until after the display, as in the studies of Reicher and Wheeler, than when they are known in advance, as in the standard detection procedure. Also, when the letter is embedded in a word, redundant information bearing upon identification of the letter is carried by adjacent letters owing to the nonchance distribution of frequencies of letter combinations in English text. It is difficult to design a procedure which fully eliminates the possibility that this redundant information may contribute to correct performance at the time of response selection. ${ }^{1}$

Our first objective in the series of experiments reported here was to determine whether a facilitative interaction of the type reported by Reicher and Wheeler would occur in the forced-choice visual detection situation when Ss knew the relevant alternatives in advance of a series of trials. Also, we introduced a control for certain possible effects of redundancy by arranging our multiple letter displays so that the replacement of the target letter with its alternative would be equally likely to change a nonword letter string into a word or a word into a nonword.

In the first experiment reported, single letter displays contained one or the other of the target letters plus nonletter mask characters which were highly dissimilar from the signal letters, as in the Estes (1972) study. In the second experiment, in order to investigate some hypotheses concerning masking effects which arose from the results of Experiment I, the nonletter noise characters in the single letter displays were in some 
Table 1

Percentage of Correct Detections by Display Type for Experiment I

\begin{tabular}{|c|c|c|c|c|c|c|}
\hline \multirow[b]{2}{*}{ Group } & \multirow[b]{2}{*}{$\mathbf{N}$} & \multirow[b]{2}{*}{$\begin{array}{c}\text { Trial } \\
\text { Sequence }\end{array}$} & \multirow{2}{*}{$\begin{array}{c}\text { Display } \\
\text { Dura- } \\
\text { tion } \\
\end{array}$} & \multicolumn{3}{|c|}{ Display Type } \\
\hline & & & & Single & Word & $\begin{array}{l}\text { Non- } \\
\text { word }\end{array}$ \\
\hline 1 & 4 & 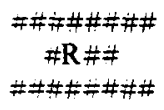 & 50 & 99 & 90 & 87 \\
\hline 2 & 4 & 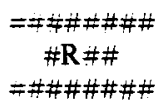 & 25 & 98 & 85 & 84 \\
\hline 3 & 4 & 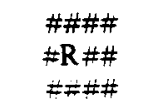 & 25 & 95 & 83 & 82 \\
\hline 4 & 4 & $\begin{array}{l}\$ \$ \$ \$ \\
=R \neq= \\
\$ \$ \$ \$\end{array}$ & 25 & 57 & 55 & 57 \\
\hline 5 & 5 & $\begin{array}{l}=\mathrm{R}= \\
\$ \$ \$ \$\end{array}$ & 25 & 85 & 85 & 86 \\
\hline 6 & 5 & $\begin{array}{l}=\mathrm{R} \# \# \\
\$ \$ \$ \$\end{array}$ & 15 & 82 & 85 & 80 \\
\hline
\end{tabular}

instances replaced with blank spaces. Pre- and postmask conditions and exposure durations were systematically manipulated in order to determine the conditions, if any, under which a facilitative effect of word context would appear in a detection paradigm and, further, to elucidate the role of inhibitory interactions in the various types of displays investigated.

\section{EXPERIMENT I}

\section{Method}

\section{Apparatus}

Character displays were presented on the screen of a Tektronix 564B oscilloscope, used in the normal (nonstorage) mode, and controlled by a PDP-8/I computer. The S sat at a table with a response box centered in front of him and faced a $51 \times 51 \mathrm{~cm}$ black panel $32 \mathrm{~cm}$ from the edge of the table. The screen of the oscilloscope, $11 \mathrm{~cm}$ wide $\times 8 \frac{1}{2} \mathrm{~cm}$ high, was visible through a $12 \times 10 \mathrm{~cm}$ aperture in the panel. The two response buttons, which activated microswitches interfaced to the computer, were $2.0 \mathrm{~cm}$ deep and $2.7 \mathrm{~cm}$ wide, with a $0.6-\mathrm{cm}$ space between them.

Character displays were constructed by illuminating the appropriate pattern of points in a matrix 6 points high by 5 points wide. Characters were approximately $.75 \mathrm{~cm}$ high and $.60 \mathrm{~cm}$ wide. At the normal viewing distance, the width of a character subtended approximately $.75 \mathrm{deg}$ and the intercharacter space slightly less than $.5 \mathrm{deg}$.

\section{Procedure}

The Ss in both experiments were young adults, in most cases obtained through newspaper advertisements, who were paid for their services.

The Ss were informed about the general nature of the experiment but were not told about the particular types of displays that would be included. They received no information concerning correctness of their responses.
Under the premask condition, a trial began with a 2-sec exposure of a row of mask characters followed by the letter display for the prescribed duration and then a row of mask characters which remained in view until the $S$ operated a response key and terminated the trial. Under the preblank condition, a trial began with a $250-\mathrm{msec}$ exposure of a row of mask characters followed by a $1,750-\mathrm{msec}$ blank interval, during which the screen was dark, then the display for the prescribed duration, and finally the postmask display which remained in view until the $S$ responded.

The mask characters resembled a typed \# sign and a typed $\$$ sign and will be denoted by these symbols. The \# mask was altered slightly (by deleting some of the normally illuminated points) when necessary in order to equate average brightness of mask characters and letters within a display.

Displays of letters always occupied four positions in a horizontal row, centered on the CRT screen. In premask conditions, each position was filled by a mask character at the start of each trial, and under all conditions, each position was filled by a mask character at the end of each trial.

By means of the real-time clock in the computer, latencies from display onset to closing of a response switch were measured, accurate to $.001 \mathrm{sec}$, and both latencies and choices were typed out on a Teletype in the adjoining control room.

\section{Design}

Six groups of Ss were run under the various combinations of display durations and mask conditions summarized in Table 1. The first three groups were planned simply to provide an initial appraisal of relative detectability of letters in single, word, and nonword displays under conditions essentially identical with those used in a variety of recent tachistoscopic studies (e.g.. Estes, 1972). The eight-position displays used with Groups 1 and 2 were selected to allow for the possibility that in later experiments we might wish to vary the lateral position of the letter display as done by Wheeler (1970). However, after running the first two groups, we decided that it would be better to keep the brightness of the display more nearly constant throughout a trial, and thus, throughout the remainder of Experiment I, we used four-position displays with the positions of the four mask characters coinciding precisely with the positions of the four letters of a display.

When it proved that accuracy of detection of single letters remained extremely high even at a 25 -msec exposure duration, we replaced the $\#$-sign masks with more effective \$-sign masks which were used in the remainder of the series. We had planned to include a group run with \$-sign pre-and postmasks at $15-\mathrm{msec}$ exposure, but when it turned out that performance was little above chance at $25 \mathrm{msec}$, we felt it not worthwhile to run this condition. The preblank groups were included in view of the fact that the studies of Reicher (1969) and Wheeler (1970) had not used premasks.

The displays in which a signal element appeared were of three types: (a) words, (b) nonwords, and (c) single letters. All displays contained four serial positions. For the word and nonword displays, all serial positions of the display were occupied by letters. For the single letter displays, the three serial positions not occupied by the signal letter were filled by \# characters, chosen to be highly dissimilar from the signal letters. For all display types, the two signal elements were the letters $R$ and $\mathbf{L}$.

The word displays were constructed so that exchanging the nonpresented signal letter for the presented signal letter changed one-half of the displays into nonword displays and kept one-half of them as word displays. Similarly, exchanging the nonpresented signal letter for the presented signal letter changed one-half of the nonword displays into word displays and kept one-half of them as nonword displays. Thus, two types of word displays were used, which may be denoted $\mathrm{W}-\mathrm{W}$ and $\mathrm{W}-\mathrm{NW}$, 
respectively, depending upon whether the display remained a word or became a nonword when the presented signal letter was replaced by the nonpresented signal letter. Similarly, two types of nonword displays were used: NW-NW and NW-W.

Pairs of W-W and W-NW displays were constructed first and then used to construct pairs of NW-NW and NW-W displays, respectively. To illustrate this process, consider the pair of $W-W$ displays, PLAY and PRAY. From this pair of words, a pair of NW-NW displays was constructed by randomly rearranging the letters of the W-W display pair, except that the signal letter maintained its original serial position and the consonant-vowel structure of the original words was preserved in the transformed nonwords. Thus, YLAP and YRAP would be an acceptable pair of transformed NW-NW displays.

Now consider the words SLED and TRAY. Replacing the presented signal letter with the nonpresented signal letter in both words transforms them into the nonwords, SRED and TLAY, respectively. Thus, the pair SLED-SRED and the pair TRAY-TLAY are W-NW displays when the word member of the pair is presented, but they are transformed into NW-W displays when the nonword member of the pair is presented. Each $S$ would actually be presented with each member of the above four pairs: PLAY-PRAY, YLAP-YRAP, SLED-SRED, and TRAY-TLAY, although both members of the same pair were never presented within the same block of 72 trials.

For each of the four serial positions in which the signal letter could appear, six sets each containing four pairs of displays were constructed according to the scheme described above. Thus, 24 pairs of W-W, NW-NW, W-NW, and NW-W display types were constructed. Each $S$ received all 96 of these pairs for a total of 192 four-letter displays, of which 96 were words and 96 were nonwords. In addition, the $S$ was presented with 96 single letter displays

The total set of 288 experimental displays was divided into blocks of 72 trials. Any one block of 72 trials contained equal numbers of word, nonword, and single letter displays, with $\mathrm{R}$ and $L$ appearing equally of ten in each serial position in each display type. Each $\mathrm{S}$ received a different random ordering of the four blocks of trials. In addition to the four experimental trial blocks, each $S$ received a practice block of 72 trials. This practice block of trials was the same for all Ss and was constructed in the same manner as were the experimental trial blocks. The procedure was the same during the practice block and the experimental blocks for all groups except that, for the group run at a 15 -msec exposure duration, the practice block was run at $25 \mathrm{msec}$.

\section{Results}

Percentages of correct detections are summarized for each group by display type in Table 1 . The most conspicuous overall result is the absence of either of the effects reported in the studies by Reicher (1969) and Wheeler (1970). Under none of the combinations of conditions included is there any advantage for a letter embedded in a word as opposed to a letter embedded in a nonword, and in no case is there an advantage for a letter embedded in a word over a single letter display.

With the relatively ineffective mask used for Groups $1-3$, an advantage for single letters over letters in words obtained for every $S$, and it did not appear that the percentage of correct detections for single letter displays could be driven very far below perfect performance unless we went to extremely short exposure times. But since reducing the display duration simply reduced the accuracy of performance for single, word, and nonword
Table 2

Percentage of Correct Detections by Signal Letter and End vs Center Positions for Experiment I, Groups 4-6

\begin{tabular}{lccccc}
\hline \multirow{2}{*}{$\begin{array}{c}\text { Display } \\
\text { Type }\end{array}$} & \multicolumn{2}{c}{ Signal $\mathrm{R}$} & & \multicolumn{2}{c}{ Signal L } \\
\cline { 2 - 3 } \cline { 5 - 6 } & End & Center & & End & Center \\
\hline Single & 78 & 74 & & 82 & 74 \\
Word & 82 & 83 & 74 & 64 \\
Nonword & 79 & 79 & & 74 & 67 \\
\hline
\end{tabular}

displays proportionately, we turned instead to manipulations of the masking stimuli.

When the \#-sign mask was replaced by the more effective \$-sign mask, performance at the $25-\mathrm{msec}$ display duration dropped almost to chance. Under the same conditions, but with the premask eliminated so that a blank interval of $1.75 \mathrm{sec}$ intervened between the ready signal and the display on each trial, detection accuracy fell to an intermediate level, but in no case with any differences between single, word, and nonword conditions.

However, the overall percentages for Groups 4-6 conceal some differences among conditions which are brought out by more detailed analysis. The data for these groups were analyzed for trials on which the two signals, $\mathrm{R}$ and $\mathrm{L}$, occurred and for position of the signal letter in the display. Table 2 summarizes the percentages of correct detections for the two signal letters separately and for end vs center positions in the display. An analysis of variance for Signal Letter by Display Type yields an $F$ of less than 1 for display type, but the effect of signal letter and the interaction of the two variables are significant beyond the .01 level (Fs of 11.76 with $\mathrm{df}$ $=1 / 13$ and 6.42 with $\mathrm{df}=2 / 26$, respectively). There is an advantage for letters in words when the signal is an $R$ but an advantage for the single letter condition when the signal is an L. The interaction is in the same direction, though less marked, for the interaction of Signal Letter by Single vs Nonword Condition. It appears that perceptibility of the letter $R$ is enhanced but that of the letter $L$ is depressed when the letter is embedded in a string, whether or not the string is a meaningful word, with the effect being stronger at the center than at the end positions.

Mean reaction times (RT) for correct detection responses were obtained by serial position for each of the display types for Groups 4-6. The only appreciable effects on reaction time are attributable to the presence or absence of a premask and to the exposure duration. Overall mean correct RT for Group 4, run with the premask at $25-\mathrm{msec}$ exposure, was 1.25 , that for Group 5, run without the premask at the same exposure, was .83 , and that for Group 6 , run without the premask at $15-\mathrm{msec}$ exposure, was .93 -all of these differences being highly reliable by $t$ tests. However, there were no differences across display types, mean RTs running .99 , 1.02 , and $1.00 \mathrm{sec}$ for the single, word, and nonword conditions, respectively, pooled over Groups 4-6. 
Table 3

Percentage of Correct Detections by Display Type for Experiment II

\begin{tabular}{|c|c|c|c|c|c|c|}
\hline \multirow[b]{2}{*}{ Group } & \multirow[b]{2}{*}{$\mathbf{N}$} & \multirow[b]{2}{*}{$\begin{array}{c}\text { Trial } \\
\text { Sequence }\end{array}$} & \multirow{2}{*}{$\begin{array}{c}\text { Display } \\
\text { Dura- } \\
\text { tion }\end{array}$} & \multicolumn{3}{|c|}{ Display Type } \\
\hline & & & & Single & Word & $\begin{array}{l}\text { Non- } \\
\text { word }\end{array}$ \\
\hline 7 & 4 & $\begin{array}{l}\text { SSSS\$S\$S } \\
\mathrm{R}= \\
\$ \$ \$ \$ \$ S \$ \$\end{array}$ & 25 & 83 & 83 & 78 \\
\hline 8 & 4 & 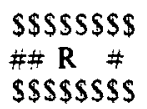 & 15 & 61 & 56 & 60 \\
\hline 9 & 4 & $\begin{array}{l}\mathrm{R} \# \\
\text { \$SS\$\$S\$\$ }\end{array}$ & 25 & 90 & 85 & 85 \\
\hline 10 & 4 & $\begin{array}{l}\#=R \# \\
\text { SSSSSSSS }\end{array}$ & 15 & 82 & 72 & 72 \\
\hline
\end{tabular}

Serial position functions were uniformly extremely flat, with no appreciable or significant differences across positions for any of the display types.

\section{EXPERIMENT II}

In the first experiment, we found that the substantial superiority of single letter displays over word or nonword displays which obtained with the longest exposure time and less effective mask conditions was accentuated when exposure time was reduced, but eliminated by a change to more effective mask conditions.

A hypothesis which suggests itself by way of explanation is that, under the easier mask conditions, characters at all positions are processed in terms of the critical features which make up characters (Estes, 1972; Rumelhart, 1970) and that inhibitory interactions among the input channels to feature detectors yield reduced recognizability of a letter if it is embedded in a string. The inhibitory interactions would be similar in word and nonword displays, but would be more effective at shorter exposure times. With the introduction of more effective masks in Groups 4-6, however, the input from all positions is degraded and in a substantial proportion of cases is insufficient to excite feature detectors. Under these conditions, lateral inhibitory effects occur below the level of feature detectors and the \#-sign mask, when used as a noise character, is just as effective as other letters in reducing the perceptibility of the target letter.

Further, a simple test of this hypothesis comes immediately to mind. If the idea is sound, then it should be possible to restore the single letter advantage simply by eliminating the \#-sign mask characters adjacent to the target letter in the single letter displays while all other conditions are unchanged. To check out this interpretation, the present experiment replicates the conditions of Groups 4-6 of Experiment I, but with the addition of a $15 \cdot \mathrm{msec}$ premask group, the only changes in display conditions being those needed to replace mask characters adjacent to target letters with spaces in the case of single letter displays.

\section{Method}

The apparatus, the $S$ population, all general procedures, and the specific letter strings which provided the displays under the single, word, and nonword conditions were all unchanged from Groups 4-6 of Experiment I. In the present experiment, exposure durations of 25 and $15 \mathrm{msec}$ were combined factorially with presence or absence of a premask, four Ss being assigned to each combination.

The display conditions on a trial can be most easily understood with reference to the third column of Table 3 . If we denote the eight display positions utilized on any trial by the numbers 1-8, the letter displays for the word and nonword conditions occupied Positions 3, 4, 5, and 6 and the $\$$-sign mask characters occupied Positions 1-8 for all conditions. The makeup of the single displays was a bit more complicated. Positions 3,4 , 5 , and 6 contained blank spaces, except for the one position occupied by the target letter R or L. Further, in each of these displays, Positions 2 and 7 plus either Position 1 or Position 8 (in a counterbalanced arrangement) were filled with modified \#-sign masks. The purpose of this manipulation was to keep the total number of points illuminated on the screen equated between single, word, and nonword displays. The modifications in the \#-sign mask characters referred to above consisted simply of eliminating dots where needed in order to maintain the average number of points illuminated at the values needed to produce equal brightness of the two target characters in the single letter as compared to multiple let ter displays.

It should be remarked that the use of eight-character pre- and postmasks resulted in the one change of conditions for this experiment as compared to Experiment I which would not be apparent from the schemata in Tables 1 and 3. Namely, owing to the manner in which the computer maintains displays on the screen by cyclically refreshing the illumination of the various individual points, there is necessarily a variation in brightness with the number of points illuminated. Consequently, with the eight-character masks the brightness was somewhat reduced as compared to the four-character masks of Groups 4-6 of Experiment I, whereas the brightness of the letter displays themselves was identical in the two experiments.

\section{Results}

The overall percentages of correct detections by display types, summarized in Table 3 , show a pattern not very different from that of Groups 4-6 of Experiment I. In the case of the preblank conditions, the quantitative correspondence is quite close, except that an advantage for the single letter displays reappears in the present data. For the premask condition with 25-msec duration, the percentages correct are somewhat higher than for the corresponding condition in Experiment I, probably because of the reduced intensity of the premask stimuli in Experiment II.

Because only the single letters in the middle positions are surrounded by spaces in the present experiment, primary interest attaches to the analysis by serial positions. Detection percentages for the two signal letters separately are given for the end and center display positions in Table 4. An analysis of variance of these 
data shows the effects of display type and its interaction with position to be significant at the .01 level (Fs of 6.06 and 12.55, respectively, each with $\mathrm{df}=2 / 30$ ). Unlike Experiment I, effect of signal letter is not significant.

As predicted from the hypothesis which led to this experiment, the principal effect is the appearance of a substantial advantage for single letters over letters in words or nonwords at the center display positions, these differences being significant beyond the $1 \%$ level by $t$ tests. But at the end display positions, where the target letter in the single display has a mask character adjacent to it, the interaction found in Exporiment I appears again, though to a slightly reduced degree, the word and nonword displays having an advantage for Signal Letter R and the single displays for Signal Letter $L$.

Serial position functions, with percentages of correct detections broken down by premask vs preblank conditions for each display type, are presented in Table 5. It is of interest to note that in the case of single letter displays, the effect of the premask is to reduce detectability sharply at the end positions but with very little effect at the middle positions, in agreement with the findings of Merikle and Coltheart (1972) and Matthews (1972). No such differential appears, however, for the word or nonword displays.

Analyses of reaction times on correct detection trials yield a picture similar to that of Experiment $I$ in most respects. The one notable difference is that in Experiment II, mean correct RT is shorter for the single than for the word or nonword conditions, the means being $.77, .85$, and $.83 \mathrm{sec}$, respectively. Again, the serial position functions are relatively flat, with RTs somewhat shorter at the center positions for the single displays, the means across positions running $.79, .74, .73$, and .81 , respectively, in the present experiment as compared to $1.0, .95, .97$, and 1.04 for Groups 4.6 of Experiment I. Again in this experiment, elimination of the premask resulted in an appreciable reduction in RTs; however, in this case the reductions were uniform across serial positions for all display types.

\section{DISCUSSION}

With the detection procedure, in which the $\mathrm{S}$ knows in advance of a series of trials the signal letters which he is to attempt to detect against a noise background, we

Table 4

Percentage of Correct Detections by Signal Letter and End vs Center Position for Experiment II

\begin{tabular}{lccccc}
\hline \multirow{2}{*}{$\begin{array}{c}\text { Display } \\
\text { Type }\end{array}$} & \multicolumn{2}{c}{ Signal } & & & \multicolumn{2}{c}{ Signal } & L \\
\cline { 2 - 3 } \cline { 5 - 6 } & End & Center & & End & Center \\
\hline Single & 70 & 85 & & 77 & 85 \\
Word & 75 & 76 & & 72 & 72 \\
Nonword & 79 & 75 & & 74 & 68 \\
\hline
\end{tabular}

Table 5

Percentage of Correct Detections by Serial Position and Mask Condition for Experiment II

\begin{tabular}{llllll}
\hline \multirow{2}{*}{$\begin{array}{l}\text { Display } \\
\text { Type }\end{array}$} & Mask & 1 & 2 & 3 & 4 \\
\cline { 3 - 6 } Single & Premask & 65 & 80 & 74 & 57 \\
& Preblank & 76 & 84 & 86 & 84 \\
\multirow{3}{*}{ Word } & Premask & 64 & 68 & 68 & 64 \\
& Preblank & 81 & 77 & 72 & 72 \\
\multirow{2}{*}{ Nonword } & Premask & 70 & 64 & 64 & 67 \\
& Preblank & 84 & 76 & 72 & 72 \\
\hline
\end{tabular}

have found no overall advantage for letters embedded in words. Rather, we have obtained a pattern of facilitatory and inhibitory effects of context which seems more readily interpretable in terms of masking than of semantic relations or perception of higher order units.

Under display conditions which yield high performance levels, i.e., detection probabilities greater than $90 \%$ for single letters, we have uniformly found single letter displays superior to either words or nonwords and no difference between the latter. For low performance conditions, we have found that, on the average, detectability is equal in all three types of displays.

We have also found indications that these average results need to be interpreted with considerable caution. In particular, some substantial and significant differences have appeared with respect to the two signal letters, $R$ and $\mathrm{L}$, used in this study-the letter $\mathrm{R}$ being slightly more detectable when embedded in a word or nonword string than when presented in a homogeneous noise background, whereas the letter $\mathrm{L}$ is much less readily detected when embedded in a string. It should be emphasized that the facilitative effect of a word or nonword context on identifiability of the letter $R$ appears only if we compare identification of the letter when flanked by other letters with identification of the same letter when flanked by noise characters. In no case have we found any evidence of facilitation when the control condition is one in which the letter appears without adjacent letters or noise characters.

It does not seem likely that these interactive effects arise from differences in identifiability of the two letters $\mathrm{R}$ and $\mathrm{L}$ taken by themselves. In the present data, the differences between the two were very slight when they appeared alone in displays, and Uttal and Smith (1968) report equal scores for the letters $\mathrm{R}$ and $\mathrm{L}$ on single letter recognition tests. The interactions arise, rather, from a depression in recognizability of the letter $L$ when it is embedded in a letter string, the depression being greater for center than for end positions. Conceivably, this difference is related to the fact that the letter $R$ occurs more frequently in English texts than does the letter $\mathrm{L}$, and in particular occurs substantially more frequently as the second letter of bigrams (Underwood \& Schulz, 1960). However, it seems unlikely that this 
variable is materially implicated in view of the uniform absence of word vs nonword differences in our data.

A more plausible source of the $R$ vs $L$ interaction lies in the greater complexity of the letter $R$. In the distinctive feature representations of capital letters presented by Gibson (1969), R has five features and L only three, one of these being shared by the two letters. Thus, in terms of the interactive channels model, $\mathrm{L}$ would be expected to suffer more interference than $R$ when embedded in a string of other letters. Having more features, $\mathrm{R}$ would exert greater lateral inhibitory effects on adjacent letters and therefore would undergo less masking itself. Further, if one or two of its features were rendered ineffective by masking from adjacent letters, $R$ would remain relatively distinguishable, whereas $L$ would be indistinguishable from many other letters.

In terms of the ideas which led to this study, we assume that the \#-sign masking stimulus has fewer letter features in common with the target letters than do other letters of the alphabet, at least on the average. Consequently, it was anticipated that embedding a target letter in a row of \#-sign noise stimuli would yield higher detectability than would embedding the same letter in a string of other letters, and this expectation was clearly confirmed in Groups 1-3 of Experiment I.

Similar considerations enter into the interpretation of the effects of pre- and postmasks. Why should the change from a \#-sign to a \$-sign masking stimulus in the pre- and postmask displays (Groups 1-3 vs Groups 4-6 of Experiment I) have depressed the detectability of target letters, and more strongly when they occurred alone than when they occurred in word or nonword strings? Among the possible interpretations which come to mind is that when the \#-sign mask was used in the pre- and postmask displays, then for the single condition there was no change in the stimulus pattern at any position except that occupied by the target letter from the premask to the display to the postmask within a trial. Contrariwise, under the conditions of Groups 4-6, all positions changed simultaneously from the premask to the display and then again to the postmask. And, of course, all positions always changed in the case of word and nonword strings. However, it does not seem that this difference could provide a sufficient explanation of the single letter advantage, for in the premask conditions of Experiment II of the present study, the stimuli changed from the premask to the display at all positions on single trials as well as on word and nonword trials, but a single letter advantage was observed only when the single letter occurred at the interior positions of the single displays.

We suggest that these effects can be more simply interpreted in terms of inhibitory interactions among elements of the display and between these and masking stimuli. The greater effectiveness of the $\$$ than of the \# mask is explainable in terms of the difference in number of critical features (seven for $\$$ vs four for \# on our interpretation of Gibson's schema). It may be necessary, however, to introduce a distinction which was not explicitly included in the interactive channels model outlined by Estes (1972). Namely, it appears that we may need to take account of masking at a subfeature level as well as at the level of the critical features which comprise characters. For the groups rin with the \#-sign masks in Experiment $I$, it is likely that characters appearing at all positions of the displays were processed to the level of feature identification. Although we do not have systematic data on the point, this idea is suggested by the comments on the part of many of our Ss who were run with the \#-sign masks that they frequently could see whole words, whereas this was virtually never the case for $\mathrm{Ss}$ run with the $\$$-sign masks. In fact, with the $\$$-sign masks, it is the impression of the Es and a number of other sophisticated observers that it is rarely possible, particularly at a $15-\mathrm{msec}$ exposure, to see even single letters clearly-a typical introspective report being that the observer had the impression that a letter $\mathrm{R}$ or $\mathrm{L}$ was present but had not actually seen it and could not specify its position. Thus, under the conditions of the \#-sign pre- and postmask, inhibitory interactions among feature detectors would arise from all positions of the displays in the case of word and nonword strings, but these would be reduced in the case of single displays, since the \#-sign character has few features in common with target letters.

When the highly effective $\$$-sign stimuli were used for pre- and postmasks, we should expect on the basis of the literature on forward and backward masking that, to some extent, stimulation from these mask stimuli would be integrated with stimuli from the characters of the display, thus reducing identifiability of the latter. In the case of the target letter, the result of this process would be a degradation of the input from the target letter position so that, in general, not all of the appropriate feature detectors would be excited. At other positions in the display, similar degradation would occur, the result being incomplete representations of other letters of the display in the case of word and nonword strings and some composite of the $\$$-sign mask stimulus and the \#-sign noise stimulus at positions other than that of the target letter in the case of the single displays. Lateral inhibitory or masking effects among the fragmentary, degraded inputs from various character positions under the \$-sign mask condition would be assumed to occur at a lower, and quite likely more peripheral, level of processing than that which occurs among features and would be similar in degree for the single, word, and nonword conditions.

Our results seem to fit in extremely well with those of Turvey (1973), who investigated the effects of a pattern mask (i.e., one made up of line segments which might correspond to critical features of letters) and a random noise mask and showed that only the pattern mask is effective in dichoptic presentation, whereas the random noise mask is effective when presented monoptically; this suggests that lateral inhibitory effects below the level of features occur peripherally, presumably at a retinal level, whereas those involving interactions among feature detectors occur centrally. 
The rather sharp disparities between our findings and those of Reicher (1969) and Wheeler (1970) with regard to the facilitative effects of words as context for letter recognition may be interpretable in terms of procedural differences. Perhaps the most salient procedural difference between the two types of studies is that in our detection experiments, the $S$ always knows in advance of a series of trials precisely what target letters he is attempting to detect, whereas in the experiments of Reicher and Wheeler, the target letters for a trial are presented following the stimulus display in the form of a postexposure cue. Thompson and Massaro (1973) suggest that the informational constraints arising from the redundancy of letter combinations occurring in words as compared to nonwords are adequately controlled only under the former conditions. Our results indicate that once differential effects of redundancy are eliminated, the remaining influences of word or nonword context are attributable to processes of lateral masking.

\section{REFERENCES}

Eriksen, C. W., \& Rohrbaugh, J. W. Some factors determining efficiency of selective attention. American Journal of Psychology, 1970, 83, 330-342.

Eriksen, C. W., \& Spencer, T. Rate of information processing in visual perception: Some results and methodological considerations. Journal of Experimental Psychology Monograph, 1969, 79(No. 2).

Estes, W. K. Interactions of signal and background variables in visual processing. Perception \& Psychophysics, 1972, 12, 278-286.

Estes, W. K., \& Wolford, G. L. Effects of spaces on report from tachistoscopically presented letter strings. Psychonomic Science, 1971, 25, 77-80.

Gibson, E. J. Principles of perceptual learning and development.
New York: Appleton-Century-Crofts, 1969.

Matthews, M. L. Masking of letters as a function of retinal eccentricity. Paper read at the Psychonomic Society meetings, St. Louis, Missouri, November 1972.

Merikle, P. M., \& Coltheart, M. Selective forward masking. Canadian Journal of Psychology, 1972, 26, 296-302.

Reicher, G. M. Perceptual recognition as a function of the meaningfulness of the material. Journal of Experimental Psychology, 1969, 81, 275-280.

Rumelhart, D. E. A multicomponent theory of the perception of briefly presented displays. Journal of Mathematical Psychology, 1970, 7, 191-218.

Shiffrin, R. M., \& Geisler, W. A model for visual information processing. Paper read at the Mathematical Psychology meetings, San Diego, August 1972.

Thompson, M. C., \& Massaro, D. W. Visual information and redundancy in reading. Journal of Experimental Psychology, 1973 , in press.

Turvey, M. T. On peripheral and central processes in vision: Inferences from an information-processing analysis of masking with patterned stimuli. Psychological Review, 1973, 80, 1-52.

Underwood, B. J., \& Schulz, R. W. Meaningfulness and verbal learning. New York: Lippincott, 1960.

Uttal, W. R., \& Smith, P. Recognition of alphabetic characters during voluntary eye movements. Perception \& Psychophysics, 1968, 3, 257-264.

Wheeler, D. D. Processes in word recognition. Cognitive Psychology, 1970, 1, 59-85.

\section{NOTE}

1. The problems involved have been clarified by Thompson and Massaro (1973) in a study which came to our attention after this passage was written. We are indebted to Dr. Massaro for making this report and other results from his series of studies available to us in advance of publication.

(Received for publication January 15, 1973; accepted January 21, 1973.) 